\title{
Organophosphorus Pesticide in Sapodilla (Manilkara zapota) Fruit
}

\author{
Daniel B. Alcântara, ${ }^{a}$ Mario S. O. Paz, ${ }^{a}$ Tigressa H. S. Rodrigues, ${ }^{b}$ \\ Tatiana S. M. Fernandes, ${ }^{c}$ Pablo G. A. Barbosa, ${ }^{a}$ Adonay R. Loiola,${ }^{d}$ Patricia Grinberg, ${ }^{e}$ \\ Guilherme J. Zocolo, ${ }^{f}$ Edy S. de Brito ${ }^{f}$ and Ronaldo F. do Nascimento ${ }^{*, a}$ \\ ${ }^{a}$ Departamento de Química Analítica e Fisico-Química, Universidade Federal do Ceará, \\ R. Humberto Monte S/N, Pici, 60455-700 Fortaleza-CE, Brazil \\ ${ }^{b}$ Departamento de Química, Universidade Estadual Vale do Acaraú, \\ Av. Universidade 850, 62040-370 Sobral-CE, Brazil \\ ${ }^{c}$ Departamento de Engenharia Hidráulica e Ambiental, Universidade Federal do Ceará, Bloco 713, \\ Avenida Humberto Monte S/N, Campus do Pici, 60451-970 Fortaleza-CE, Brazil \\ ${ }^{d}$ Departamento de Química Orgânica e Inorgânica, Universidade Federal do Ceará, \\ R. Humberto Monte S/N, Pici, 60455-700 Fortaleza-CE, Brazil \\ ${ }^{e}$ National Research Council Canada, 1200 Montreal Rd, K1A0R6 Ottawa, Canada
}

${ }^{f}$ Embrapa Agroindústria Tropical, R. Dra Sara Mesquita, 2270, 60511-110 Fortaleza-CE, Brazil

\begin{abstract}
A method based on QuEChERS (quick, easy, cheap, effective, rugged, and safe) extraction and gas chromatography-mass spectrometry (GC-MS) detection was described for the pesticides dichlorvos, disulfoton, ethoprophos, parathion methyl, fenchlorphos, chlorpyrifos, azinphos methyl and prothiofos in sapodilla. For all compounds studies, it was observed a strong matrix effect showing the need to use matrix matched calibration strategy. Method was validated, and good linearity $(\mathrm{R}>0.99)$ was obtained for all pesticides studied with limits of detection (LODs) and quantification (LOQs) ranging from 0.01 to $0.06 \mathrm{mg} \mathrm{kg}^{-1}$ and 0.03 to $0.2 \mathrm{mg} \mathrm{kg}^{-1}$, respectively. Recovery studies were performed at different levels $\left(0.08,0.10,0.14,0.20,0.35\right.$ and $\left.1.17 \mathrm{mg} \mathrm{kg}^{-1}\right)$ and showed good results (between 70 and $120 \%$ with relative standard deviation (RSD) $<20 \%$ ). A statistical test was applied to the coefficients of the analytical curves obtained in the sapodilla matrix. Analyses of commercial samples showed chlorpyrifos were detected in about 70 and 33\% for fruit and pulps samples, respectively. It should be noted that chlorpyrifos is not permitted in sapodilla crops by ANVISA and EC guidelines.
\end{abstract}

Keywords: QuEChERS, validation, matrix effect, GC-MS

\section{Introduction}

The sapodilla (Manilkara zapota) is a fruit native to southern Mexico and Central America which had good adaptability to Brazil, mainly in the northeastern part of the country, due to the favorable climatic conditions. ${ }^{1,2}$

Considered to be the 'fruit honey of the tropics' by the Brazilian Agricultural Research Company (Embrapa), consumer's consumption of sapodilla has increased in the last years due to its nutritional benefits along with the pleasant sensory characteristics such as its aroma and flavor. ${ }^{3}$ It is commonly used as a raw material for ice cream,

*e-mail: ronaldo@ufc.br pudding, candy, pulp, besides being quite consumed in its nature form. Among all considered exotic fruits in Brazil, it is considered to be the one with the greatest potential for economic exploration. ${ }^{3}$

However, it can also be a source of toxic substances due to the application of pesticides in the crops. ${ }^{4}$ In 2010 , the application of pesticides in Brazil increased twice the world average. ${ }^{5}$ The deleterious action of pesticides can cause a range of clinical manifestations, such as nausea, lack of appetite, headaches, allergies and can be also linked to different forms of cancer, genetic alterations and neurological effects. ${ }^{6,7}$

In Brazil, there are over 800 compounds belonging to more than 100 different chemical classes applied 
as pesticides in different crops. ${ }^{8}$ According to the last monitoring of the Brazilian National Health Surveillance Agency (ANVISA), ${ }^{9}$ organophosphorus (OPPs) pesticides were detected in a wide variety of fruits and vegetables.

They are commonly used as insecticides, acaricides, nematicides and fungicides. ${ }^{10}$ Due to their low cost, high efficiency and wide usage spectrum, they are the most extensively used group of pesticide. ${ }^{11,12}$ Therefore, it is necessary to develop efficient and reliable analytical procedures for the determination of OPPs pesticides residues in foods, mainly in unusual fruits such as sapodilla since no legislation have been implemented for those products.

Since the majority of the OPPs are volatile and thermally stable, they are amenable to gas chromatography (GC) analysis. ${ }^{13}$ Gas chromatography coupled to mass spectrometry (MS) with electron impact ionization has frequently been applied for the analysis of pesticide residues in different matrices with a high efficiency. ${ }^{14,15}$ The single quadrupole analyzer is the most common instrument used in the coupling of GC-MS due to its low cost and ability to work in the selective ion monitoring mode (SIM) or extracted ion (EI) monitoring mode in order to increase the selectivity and sensitivity in addition to allow the possibility of confirmation of the investigated compound. ${ }^{16}$ The advantage of the EI over the SIM is that there is no necessity in performing another chromatographic run to monitor specific $\mathrm{m} / \mathrm{z}$ ratios corresponding the analyte of interest, once the EI mode allows selecting some values of $\mathrm{m} / \mathrm{z}$ within the monitored range in total ion chromatogram (TIC) mode, and only the chromatogram containing them appears on the screen.

Since fruits have very complex matrices and generally the concentrations of pesticides are in ppb levels, a sample preparation step is required prior to instrumental analysis. ${ }^{17}$ Current trends prioritize the development of procedures for sample preparation that comply with the principles of green chemistry, e.g., decreasing the organic solvent consumption. Anastassiades et al. ${ }^{18}$ introduced a new method for the extraction of pesticides, which was mainly applicable to fruits and vegetables to overcome the practical limitations of multiresidue extraction methods that are generally time-consuming and laborious. This method is described as quick, easy, cheap, effective, rugged and safe (QuEChERS). ${ }^{18}$ In comparison with other techniques, the QuEChERS method has proven to have several advantages due to it giving excellent recoveries, involving less time and less solvent consumption. ${ }^{19-23}$

As far as the authors know, an analytical methodology for the determination of pesticide residues in sapodilla has not been reported. The purpose of the present work was to develop and validate a methodology for the determination for eight OPPs (dichlorvos, ethoprophos, disulfoton, parathion-methyl, fenchlorphos, chlorpyrifos, prothiofos and azinphos-methyl) in sapodilla samples using the QuEChERS/GC-MS method, as well as to determine the matrix effects for the evaluated analytes during the analyses of sapodilla.

\section{Experimental}

\section{Chemicals and reagents}

Acetonitrile 99.9\% $\left(\mathrm{v} \mathrm{v}^{-1}\right)$, methanol $99.97 \%\left(\mathrm{v} \mathrm{v}^{-1}\right)$, $n$-hexane $99.97 \%\left(\mathrm{v} \mathrm{v}^{-1}\right)$, anhydrous magnesium sulfate P.A., sodium chloride P.A. and trisodium citrate dihydrate P.A. were purchased from Vetec (Brazil). The sodium hydrogen citrate sesquihydrate P.A. was obtained from Sigma-Aldrich (Brazil). Primary secondary amine (PSA) and graphitized carbon black (GCB) were purchased from Supelco (USA). Water was purified by a Milli-Q (Millipore, Academic, USA) system (18.2 M $\Omega \mathrm{cm})$.

The standard solution (2000 $\mathrm{mg} \mathrm{L}^{-1}$ in $n$-hexane) for eight OPPs pesticides (dichlorvos, disulfoton, ethoprophos, parathion methyl, fenchlorphos, chlorpyrifos, methyl azinphos and prothiofos) was purchased from SigmaAldrich (Brazil). A stock standard solution $\left(10 \mathrm{mg} \mathrm{L}^{-1}\right)$ was prepared in $n$-hexane. To determine the linear range of each analyte were obtained work standard solutions of $5,10,15,25,50,75,100,150,200,250,500,1000,1500$, 2000 and $2500 \mu \mathrm{g} \mathrm{L}^{-1}$; however, the analytical curves (concentration $\times$ area) in the solvent and matrix, for each compound, were constructed using five concentration levels starting from their limits of quantification (LOQs). All standards were stored under refrigeration at $4{ }^{\circ} \mathrm{C}$ until use.

\section{Sample collection}

Sapodilla's samples were collected randomly in ten different supermarkets of the city of Fortaleza, Ceará, Brazil. Samples (4 fruits from each supermarket) were crushed, homogenized using an industrial blender, placed in amber glass bottles, sealed and stored under refrigeration at $4{ }^{\circ} \mathrm{C}$ until use. Samples were named S1, S2, S3, S4, S5, $\mathrm{S} 6, \mathrm{~S} 7, \mathrm{~S} 8, \mathrm{~S} 9$, and S10, respectively, for each supermarket.

Commercial pulps of three different brands were also collected. They were also placed in amber glass bottles, sealed and stored under refrigeration at $4{ }^{\circ} \mathrm{C}$. Samples were named B1, B2, and B3, respectively, for each brand.

\section{QuEChERS extraction}

The samples of fruit and commercial pulp of sapodilla were analyzed according to the QuEChERS method. ${ }^{24}$ 
Basically, a portion of $10.0 \mathrm{~g}$ of sample was weighed into a $50.0 \mathrm{~mL}$ polypropylene centrifuge tube. Ten milliliters of acetonitrile was added, and the resulting solution was shaken by vortex mixing $(1 \mathrm{~min})$ to ensure that the solvent interacted well with the matrix. Next, the QuEChERS extraction sorbents $\left(4.0 \mathrm{~g} \mathrm{MgSO}_{4}, 1.0 \mathrm{~g} \mathrm{NaCl}, 1.0 \mathrm{~g}\right.$ trisodium citrate dihydrate and $0.5 \mathrm{~g}$ disodium hydrogen citrate sesquihydrate) were added, and the final mixture was also shaken by vortex mixing $(2 \mathrm{~min})$ to prevent salt agglomeration. Afterwards, the extracts were then centrifuged for $10 \mathrm{~min}$ at $1008 \times \mathrm{g}$ (centrifuge Kindly, $\mathrm{KC} 5$, Brazil). A volume of $1.0 \mathrm{~mL}$ of the extracts was transferred to a $15.0 \mathrm{~mL}$ polypropylene centrifuge tube containing clean-up sorbents $(150.0 \mathrm{mg}$ of magnesium sulfate, $150.0 \mathrm{mg}$ of PSA and $30.0 \mathrm{mg}$ of GCB). The tubes were capped tightly and vortexed for $1 \mathrm{~min}$, followed by centrifugation at $1008 \times \mathrm{g}$ for $10 \mathrm{~min}$. The extract after clean-up was transferred to an Eppendorf tube for complete solvent evaporation in a vacuum centrifuge (SpeedVac, Thermo, Brazil). Then, the residue obtained was reconstituted in $1.0 \mathrm{~mL}$ of $n$-hexane, the same extract volume there was previously the evaporation step.

\section{Gas chromatography-mass spectrometry (GC-MS)}

A gas chromatograph (Agilent Technologies, model 7890B, USA) coupled to a mass spectrometer (Agilent Technologies, model 5977A, USA) was used in the development of the multiresidue method. The separation of the pesticides was performed using an HP5-S ms $(30 \mathrm{~m} \times 0.25 \mathrm{~mm}$ i.d. $\times 0.25 \mu \mathrm{m}$ thickness $)$ capillary column and helium (99.99\%) carrier gas at a constant flow of $1 \mathrm{~mL} \mathrm{~min}{ }^{-1}$.

The injection temperature (IT) was set at $240{ }^{\circ} \mathrm{C}$, and a $5 \mu \mathrm{L}$ volume was injected in the splitless mode. The oven temperature was programmed as follows: initial temperature of $100{ }^{\circ} \mathrm{C}$ for $1 \mathrm{~min}, 12{ }^{\circ} \mathrm{C} \mathrm{min}{ }^{-1}$ rate to $165^{\circ} \mathrm{C}$, then $10{ }^{\circ} \mathrm{C} \min ^{-1}$ rate to $300{ }^{\circ} \mathrm{C}$, and holding at $300^{\circ} \mathrm{C}$ for $2 \mathrm{~min}$, with a total run time $21.9 \mathrm{~min}$. The mass spectrometer conditions were set as follows: ionization mode, electron impact (EI), $70 \mathrm{eV}$; ion source temperature, $240{ }^{\circ} \mathrm{C}$; and transfer line temperature, $240{ }^{\circ} \mathrm{C}$.

\section{Method validation}

The analytical method was validated following the SANTE/12571/201723 and ANVISA ${ }^{25}$ guidelines. The validation parameters, including the selectivity, linearity, matrix effect, limit of detection (LOD), limit of quantification (LOQ), accuracy and precision (instrument and intra-assay precision), were determined.
The analyses were performed in the total ion chromatogram (TIC) mode, monitoring a wide range of ions $(40-400 \mathrm{~m} / \mathrm{z})$. This way was made use of the extracted ion chromatogram (EI) tool, selecting the main fragments of the mass spectrum of each analyte (one ion of quantification and two of identification) to obtain a chromatogram only for the compound of interest, thus improving the sensitivity and selectivity. Table 1 shows the retention times of pesticides and their fragments used quantitatively and qualitatively to obtain the extracted ion chromatogram of each one. The fragments were selected in agreement with the base peak, the second most intense fragment and the one corresponding the molecular ion for each pesticide evaluated.

Table 1. Retention times and fragments used to obtain EI of each pesticide

\begin{tabular}{lccc}
\hline Pesticide & $\begin{array}{c}\text { Retention } \\
\text { time / min }\end{array}$ & $\begin{array}{c}\text { Molar mass / } \\
\left(\mathrm{g} \mathrm{mol}^{-1}\right)\end{array}$ & Fragment $(\mathrm{m} / \mathrm{z})$ \\
\hline Dichlorvos & 4.8 & 220.98 & $109,{ }^{\mathrm{a}} 185,221$ \\
Ethoprophos & 9.1 & 242.33 & $97,158,{ }^{\mathrm{a}} 242$ \\
Disulfoton & 10.9 & 274.39 & $88,{ }^{\mathrm{a}} 97,274$ \\
Parathion methyl & 11.8 & 263.21 & $109,{ }^{\mathrm{a}}$ 125, 263 \\
Fenchlorphos & 12.0 & 321.55 & $125,285,{ }^{\mathrm{a}} 320$ \\
Chlorpyrifos & 12.7 & 350.89 & $97,197,{ }^{\mathrm{a}} 351$ \\
Prothiofos & 14.3 & 345.25 & $162,267,{ }^{\mathrm{a}} 345$ \\
Azinphos methyl & 17.5 & 317.32 & $160,{ }^{\mathrm{a}} 77,317$ \\
\hline
\end{tabular}

${ }^{\mathrm{a}}$ Quantitative fragment.

Analytical standards ranging from 5 to $2500 \mu \mathrm{g} \mathrm{\textrm {L } ^ { - 1 }}$ were injected into the chromatographic system to obtain the analytical curve in the solvent. However, to construct the curve in the matrix, the sample extracts obtained after the evaporation of the acetonitrile in a vacuum centrifuge (SpeedVac, Brazil) were resuspended with each one of the analytical standards already prepared for subsequent injection into the system.

A good linear fit was found for the concentration range adopted, as it was found to approach a correlation coefficient $(\mathrm{R})$ value of one. Statistical significance tests, using the Student's $t$-test, of the calibration parameters (linear, a, and angular, b, coefficients) were applied in order to verify the adjustment of the analytical curve by the following equations: ${ }^{26}$

$\mathrm{s}_{\mathrm{a}}^{2}=\frac{\mathrm{s}_{\mathrm{y}}^{2} \sum\left(\mathrm{x}_{\mathrm{i}}^{2}\right)}{\mathrm{D}}$

$\mathrm{s}_{\mathrm{b}}^{2}=\frac{\mathrm{s}_{\mathrm{y}}^{2} \mathrm{n}}{\mathrm{D}}$ 


$$
\begin{aligned}
& \mathrm{s}_{\mathrm{y}}^{2}=\frac{\sum\left(\mathrm{d}_{\mathrm{i}}^{2}\right)}{\mathrm{n}-2} \\
& t_{\text {calc, }}=\frac{|\mathrm{b}-1|}{\mathrm{s}_{\mathrm{b}}} \\
& t_{\text {calc,a }}=\frac{|\mathrm{a}-0|}{\mathrm{s}_{\mathrm{a}}} \\
& \mathrm{D}=\left|\begin{array}{cc}
\sum\left(\mathrm{x}_{\mathrm{i}}^{2}\right) & \sum \mathrm{x}_{\mathrm{i}} \mid \\
\sum \mathrm{x}_{\mathrm{i}} & \mathrm{n}
\end{array}\right|
\end{aligned}
$$

where $s_{a}^{2}, s_{b}^{2}$ and $s_{y}^{2}$ are the square of the standard deviations of the linear coefficient, angular coefficient and $y$-axis, respectively; $\mathrm{x}_{\mathrm{i}}$ are individual values on the $\mathrm{x}$-axis; $\mathrm{n}$ is the total number of points on the analytical curve; $d_{i}$ is the vertical deviation of each point; $\mathrm{D}$ is the determinant; and $t_{\text {calc }}$ is the calculated $t$-test. If $t_{\text {calc }}$ for the parameters is greater than tabulated critical value ( $t_{\text {crit }}$, confidence level 95\%), the parameter is significant and must be kept in the equation. Otherwise, the parameter is considered insignificant and should be removed from the linear equation $(y=\mathrm{a}+\mathrm{b} x){ }^{27}$

The LODs and LOQs were estimated from successive injection of dilute solutions of the lowest concentration that resulted in signal/noise ratios of three and ten, respectively. Accuracy was demonstrated by the recovery experiments through analyzing samples spiked with pesticides at 0.08 , $0.1,0.14,0.17,0.35$ and $1.17 \mathrm{mg} \mathrm{kg}^{-1}$, performed by triplicate assay and duplicate injection. The instrument precision has been verified by the repeatability method through calculating the relative standard deviation (RSD, in percentage) of areas obtained after ten injections of the $1 \mathrm{mg} \mathrm{L}^{-1}$ standard solution into the chromatographic system, and the intra-assay precision through calculating the RSD of the recovery experiments performed in triplicate for each spiked level.

\section{Matrix effect}

The evaluation of the matrix effect caused by the sapodilla extract was performed by comparing the angular coefficients obtained by the curves in the solvent and in the matrix according to the following equation:

Matrix effect $(\%)=\frac{\left(b_{m}-b_{s}\right) 100}{b_{s}}$

where $b_{m}$ and $b_{s}$ are the angular coefficients of the curve in the matrix and in the solvent, respectively, not considering the existence of a matrix effect for relations within the range of -20 to $20 \%$. ${ }^{23,28}$

\section{Calculation of analyte concentration in the sample in $\mathrm{mg} \mathrm{kg}^{-1}$}

After the injection of a sample previously prepared by the QuEChERS method and data processing via an analytical curve, concentration results are obtained in $\mu \mathrm{g} \mathrm{\textrm {L } ^ { - 1 }}$ (weight/volume) (primary extract concentration). Thus, to obtain the estimated analyte concentration in the sample in $\mathrm{mg} \mathrm{kg}^{-1}$ (weight/weight), the following equation was used:

$\mathrm{C}_{\mathrm{F}}=\frac{\mathrm{C}_{\mathrm{ext}}\left(\mu \mathrm{g} \mathrm{L}^{-1}\right) \times \mathrm{V}(\mathrm{L})}{\mathrm{m}_{\mathrm{a}}(\mathrm{kg}) \times 1000}\left(\mathrm{mg} \mathrm{kg}^{-1}\right)$

where $\mathrm{C}_{\mathrm{F}}$ is the analyte concentration in the sample, $\mathrm{C}_{\mathrm{ext}}$ is the analyte concentration in the extract (obtained from the analytical curve), $\mathrm{V}$ is the extract volume, $\mathrm{m}_{\mathrm{a}}$ is the mass of the weighed sample and 1000 is the conversion factor from $\mu \mathrm{g}$ to $\mathrm{mg}$. This equation was used to estimate the concentration values of the analytes in commercial samples as well as the LOD and LOQ values and spiked levels.

\section{Results and Discussion}

\section{Chromatographic analysis by GC-MS}

The chromatographic conditions described previously for the GC-MS system allowed an efficient resolution for the eight OPPs pesticides. Figure 1a shows the separation profile of the analytes contained in a mixed standard solution $\left(1 \mathrm{mg} \mathrm{L}^{-1}\right)$ in the total ion chromatogram (TIC) mode, where total elution occurred in less than 20 min. Despite the low intensity relative to the azinphos methyl and the formation of two peaks that indicate dichlorvos, the compounds showed good sensitivity and selectivity.

\section{Selectivity}

The use of modern mass spectrometry detectors allows the chromatogram of the compound of interest to be extracted (extracted ion chromatogram, EI) from the total ion chromatogram (TIC). Figures $1 \mathrm{~b}, 1 \mathrm{c}$ and $1 \mathrm{~d}$ show that when using the EI tool, the method is selective for the pesticides and shows improved sensitivity (for example, ethoprophos). This tool was used for the construction of analytical curves in the matrix and for qualitative and quantitative analysis in real samples.

\section{Matrix effect and linearity}

The calibration curve in the presence of matrix was performed and compared with the one obtained in the presence of pure standards in solvent. The results (Figure 2a) 

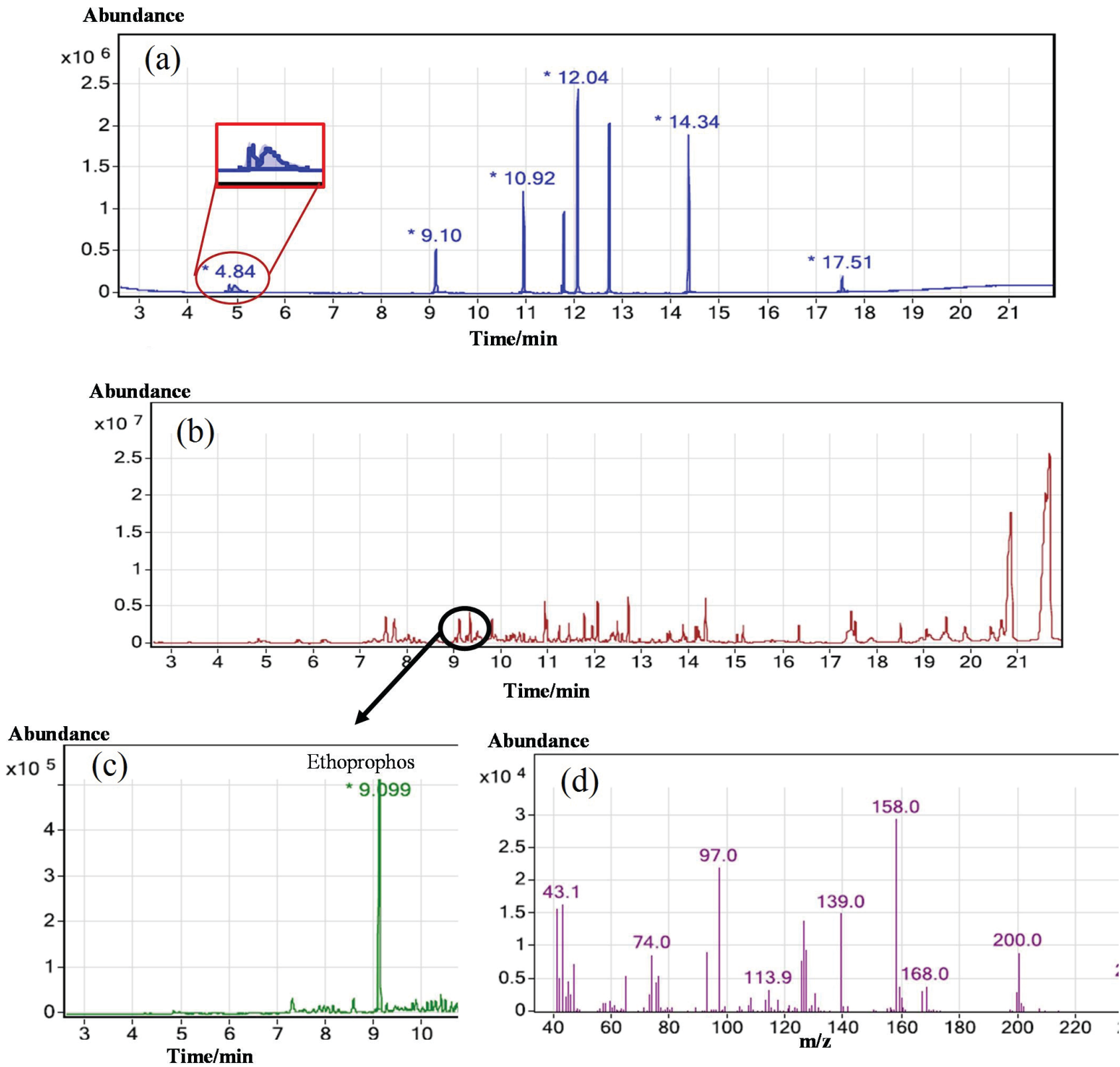

Figure 1. (a) Chromatogram obtained using an IT of $240{ }^{\circ} \mathrm{C}$ after the injection of $5 \mu \mathrm{L}$ of the standard solution of $1 \mathrm{mg} \mathrm{L}^{-1}$ in the TIC model (retention times: $4.8 \mathrm{~min}$ (dichlorvos); $9.1 \mathrm{~min}$ (ethoprophos); $10.9 \mathrm{~min}$ (disulfoton); $11.8 \mathrm{~min}$ (prathion methyl); 12 min (fenchlorphos); 12.7 min (chlorpyriphos); $14.3 \mathrm{~min}$ (prothiofos) and $17.5 \mathrm{~min}$ (azinphos methyl)); (b) total ion chromatogram of the $1.0 \mathrm{mg} \mathrm{L}^{-1}$ standard solution of pesticides in the sapodilla matrix; (c) ethoprophos extracted ion chromatogram; and (d) ethoprophos mass spectrum.

indicate that the sapodilla matrix strongly influences the analytical signals of the compounds examined. Figure $2 b$ shows the analytical curves for ethoprophos using solvent and matrix, illustrating the high occurrence of a matrix effect in sapodilla.

It has been shown that the intensity of this effect is dependent on the physicochemical properties of pesticides such as polarity, molecular weight, thermal stability, temperature of boiling analytes, etc. ${ }^{29,30}$ Negative matrix effect is observed due to degradation of the pesticide in injector or analyte adsorption on the active sites (free silanols groups) from liner. This effect causes decreasing of the analyte flux transferred to the column and consequently the decreasing of the detector signal. ${ }^{31}$ When the sample matrix is injected, there is a competitive process between the analyte and other matrix compounds to be adsorbed on liner active sites, which favors the analyte availability to the column and consequently bring an increase of the signal. ${ }^{29-31}$ Thus, the comparative responses between the analyte presented in the standard solution and in the sample matrix are characterized by an response overestimation. Probably these discussed aspects justify the positive matrix 
(a) Matrix effect $/ \%$

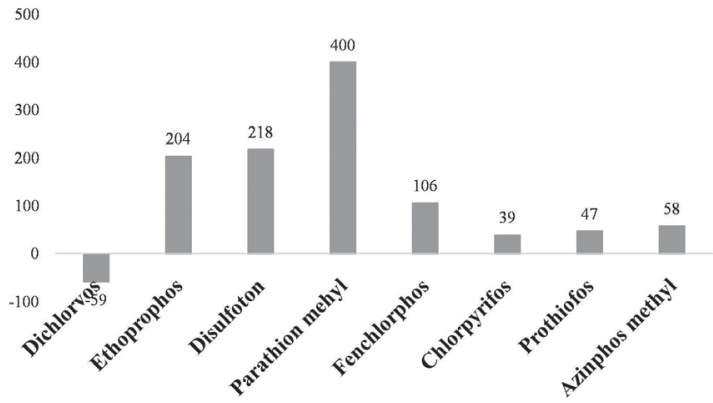

(b)

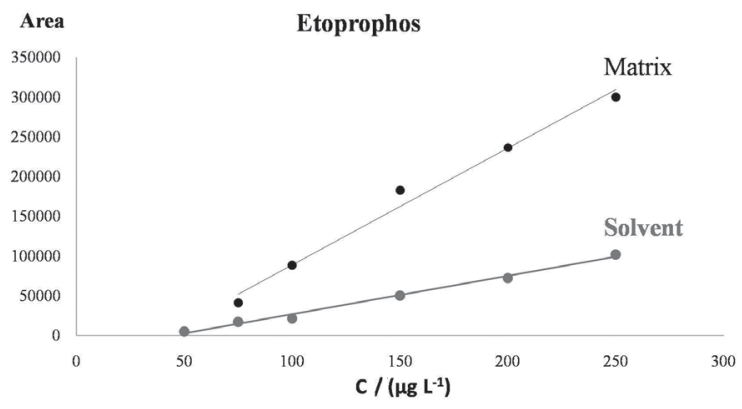

Figure 2. (a) Matrix effect of the eight pesticides in the sapodilla matrix analyzed by GC-MS; (b) superposition of solvent and matrix curves for ethoprophos.

effect observed for most pesticides studied, except for dichlorvos (Figure 2a).

Additionally, the sample nature can also influence the intensity of the matrix effect. Compounds such as lipids, pigments and other components with high molar mass are present in the sapodilla fruit. ${ }^{2,3}$ These compounds can cause the observed matrix effect for dichlorvos, which is the most hydrophilic $\left(\mathrm{K}_{\mathrm{ow}}=79.4\right)$ among the pesticides studied. Probably it is due to its interaction with high polarity compounds contained in the sample promoting a suppression in its signal (Figure 2a). ${ }^{32}$ According to Hajslová et al.,$^{33}$ normally polar compounds such as those having $\mathrm{P}=\mathrm{O}$ groups, like organophosphorus, are more susceptible to matrix effects.

Several authors have noticed matrix effect in the analysis of pesticides in different food matrices by GC-MS. Guedes et al. ${ }^{14}$ analyzed twenty one multiclass pesticides in guava samples by GC-MS and found that about $38 \%$ of them presented a positive matrix effect. Martins et al ${ }^{34}$ also observed matrix effect in the analysis of twelve multiclass pesticides in mango by GC-MS where the pesticide Y-clordano presented the strongest matrix effect with signal overestimation of almost $250 \%$.

This proposed method showed good linearity, expressed by the values of $\mathrm{R}$ near 1.00, with the lowest value being 0.993 (ethoprophos curves in the matrix), and all of the analytes were in accordance with the guidelines of ANVISA $^{25}$ that recommend values above 0.99 . However, ideally the regression line should pass through the origin, ${ }^{27,35}$ but this fact is rarely observed. Therefore, the adjustment of the analytical curve by statistical tests to minimize quantitative errors must be taken into account. For Guedes et al. ${ }^{14}$ analytical curves with a high positive value of the linear coefficient indicate contamination process (background noise, contamination in the sample preparation, etc.) and negative values generally indicate analyte losses (analyte consumption, adsorption on chromatographic columns, etc.).

Thus, the $t$-test was used for the matrix analytical curve coefficients, a procedure rarely taken into account in the literature, in order to reduce errors during the quantification of pesticide residues. Table 2 shows the results of the statistical tests of the parameters of the analytical curves prepared in the matrix as well as the values of $\mathrm{R}$, linear range obtained for each pesticide and final curves that should be used for the quantification of pesticides in commercial samples. The linear coefficients of dichlorvos, fenchlorphos, chlorpyrifos and prothiofos curves did not show statistical significance $\left(t_{\text {calc }}<t_{\text {crit }}\right)$, and they were removed from the line equation in order to achieve more accurate results.

\section{Sensitivity, accuracy and precision}

LODs and LOQs ranged from 0.01 to $0.06 \mathrm{mg} \mathrm{kg}^{-1}$ and 0.03 to $0.20 \mathrm{mg} \mathrm{kg}^{-1}$, respectively (Table 3 ). The compounds chlorpyrifos and prothiofos were shown to be the most sensitive pesticides. None of the pesticides studied have been permitted for use in the cultivation of sapodilla by ANVISA,${ }^{25}$ and consequently, there are no maximum residue limits (MRLs) available for these pesticides in sapodilla fruit. However, MRLs is available, through ANVISA $^{25}$ or European Commision (EC) ${ }^{23}$ for OPPs pesticides in several food materials as also presented in Table 3 .

Recovery studies were assessed at six levels of intentional contamination ( 0.08 to $\left.1.17 \mathrm{mg} \mathrm{kg}^{-1}\right)$, and they ranged from 42.3 to $170.76 \%$ with an RSD of 0.8 to $34.6 \%$ (Table 4). However, all pesticides had at least three concentration levels (low, medium and high) with the recovery percentages being in accordance with document SANTE/11813/201723 establishing acceptance limits of $70-120 \%$ and RSD $<20 \%$. Furthermore, it is important to consider that the accuracy is dependent on the concentration level of the analyte in the sample. In cases where the analyte is at trace levels and where there is a complex matrix, higher intervals of recovery percentages can be accepted (50 to $120 \%){ }^{36}$ Thus, the results of the recoveries of pesticides in sapodilla can be considered to be satisfactory.

The instrument precision evaluated in terms of the 
Table 2. Linearity of different pesticides in sapodilla matrix

\begin{tabular}{|c|c|c|c|c|c|c|c|c|c|c|c|c|c|}
\hline \multirow{2}{*}{ Pesticide } & \multicolumn{5}{|c|}{ Linear coefficient } & \multicolumn{5}{|c|}{ Angular coefficient } & \multirow{2}{*}{$\mathrm{R}$} & \multirow{2}{*}{$\begin{array}{l}\text { Linear } \\
\text { range / } \\
\left(\mu \mathrm{g} \mathrm{L}^{-1}\right)\end{array}$} & \multirow{2}{*}{ Final analytical curve } \\
\hline & $\mathrm{a}$ & $\mathrm{s}_{\mathrm{a}}$ & $t_{\text {calc }}$ & $t_{\text {crit }}$ & $t$-test & $\mathrm{b}$ & $\mathrm{s}_{\mathrm{b}}$ & $t_{\text {calc }}$ & $t_{\text {crit }}$ & $t$-test & & & \\
\hline Dichlorvos & -57662.2 & 39448.26 & 1.46 & 2.776 & $\begin{array}{c}\text { no } \\
\text { significant }\end{array}$ & 640.5 & 35.04 & 18.25 & 2.776 & significant & 0.9940 & $200-2000$ & $y=640.5 x$ \\
\hline Ethoprophos & -58131.20 & 16968.62 & 3.43 & 3.182 & significant & 1468.65 & 101.18 & 14.50 & 3.182 & significant & 0.9929 & $75-250$ & $y=-58131.2+1468.65 x$ \\
\hline Disulfoton & -66460.92 & 20204.78 & 3.29 & 2.776 & significant & 1978.09 & 79.19 & 24.97 & 2.776 & significant & 0.9967 & $75-500$ & $y=-66460.92+1978.09 x$ \\
\hline $\begin{array}{l}\text { Parathion } \\
\text { methyl }\end{array}$ & -171072.98 & 45396.46 & 3.77 & 3.182 & significant & 2591.80 & 163.60 & 15.84 & 3.182 & significant & 0.9975 & $100-500$ & $y=-171072.98+2591.80 x$ \\
\hline Fenchlorphos & -42710.89 & 20671.92 & 2.07 & 2.571 & $\begin{array}{c}\text { no } \\
\text { significant }\end{array}$ & 2397.25 & 87.23 & 27.47 & 2.571 & significant & 0.9967 & $50-500$ & $y=2397.25 x$ \\
\hline Chlorpyrifos & -15330.72 & 9952.23 & 1.54 & 2.776 & $\begin{array}{c}\text { no } \\
\text { significant }\end{array}$ & 1134.20 & 40.32 & 28.11 & 2.776 & significant & 0.9975 & $25-500$ & $y=1134.20 x$ \\
\hline Prothiofos & -22859.15 & 8492.14 & 2.69 & 2.776 & $\begin{array}{c}\text { no } \\
\text { significant }\end{array}$ & 1114.02 & 55.97 & 19.89 & 2.776 & significant & 0.9950 & $25-250$ & $y=1114.02 x$ \\
\hline $\begin{array}{l}\text { Azinphos } \\
\text { methyl }\end{array}$ & -274872.13 & 60664.97 & 4.53 & 2.776 & significant & 1628.99 & 53.89 & 30.21 & 2.776 & significant & 0.9978 & $200-2000$ & $y=-274872.13+1628.99 x$ \\
\hline
\end{tabular}

Table 3. LODs, LOQs and MRLs of different pesticides in sapodilla matrix

\begin{tabular}{|c|c|c|c|c|}
\hline \multirow{2}{*}{ Pesticide } & \multirow{2}{*}{$\mathrm{LOD} /\left(\mathrm{mg} \mathrm{kg}^{-1}\right)$} & \multirow{2}{*}{$\mathrm{LOQ} /\left(\mathrm{mg} \mathrm{kg}^{-1}\right)$} & \multicolumn{2}{|c|}{ MRL / $\left(\mathrm{mg} \mathrm{kg}^{-1}\right)$} \\
\hline & & & ANVISA $^{25}$ & $\mathrm{EC}^{23}$ \\
\hline Dichlorvos & 0.06 & 0.20 & - & $\begin{array}{c}\text { citrus }(0.01) \text {, apple }(0.01) \text {, grape }(0.01) \text { and } \\
\text { strawberry }(0.01)\end{array}$ \\
\hline Ethoprophos & 0.02 & 0.08 & potato $(0.05)$ & banana $(0.03)$ and pineapple $(0.03)$ \\
\hline Disulfoton & 0.02 & 0.08 & cotton $(0.20)$, coffee $(0.10)$ & - \\
\hline Parathion methyl & 0.03 & 0.10 & cotton $(0.30)$, soya $(0.10)$ & - \\
\hline Fenchlorphos & 0.02 & 0.05 & - & - \\
\hline Chlorpyrifos & 0.01 & 0.03 & $\begin{array}{l}\text { citrus }(2.00) \text {, apple }(1.00) \text {, } \\
\text { tomato }(0.50) \text {, bean }(0.10), \\
\text { coffee }(0.05)\end{array}$ & $\begin{array}{c}\text { apple }(0.50) \text {, pear }(0.50) \text {, grape }(0.50), \\
\text { pineapple }(0.30), \text { banana }(3.00), \\
\text { strawberry }(0.50) \text { and mango }(0.05)\end{array}$ \\
\hline Prothiofos & 0.01 & 0.03 & $\begin{array}{l}\text { cotton }(0.04), \text { soya }(0.03) \\
\text { tomato }(1.00)\end{array}$ & - \\
\hline Azinphos methyl & 0.06 & 0.20 & - & cashew $(0.50)$ \\
\hline
\end{tabular}

LOD: limit of detection; LOQ: limit of quantification; MRL: maximum residue limit; -: not informed.

repeatability, and the intra-assay precision (RSDs of the recovery experiments), also shown in Table 4, are in agreement to the SANTE/11813/2017 guidelines ${ }^{23}$ for most pesticide, that establishes RSDs less than $20 \%$ for multiresidue methods. Only azinphos methyl presented unsatisfactory instrument precision $(21.68 \%)$ when considering those guidelines.

\section{Analysis of commercial sapodilla samples}

The QuEChERS/GC-MS method was applied for the determination of pesticide residues in ten sapodilla fruit samples sold in supermarkets in different areas (S1, S2,
S3, S4, S5, S6, S7, S8, S9 and S10) and commercial pulps samples of three different brands (B1, B2 and B3).

From all pesticides studied, only chlorpyrifos was detected. This pesticide was presented in $70 \%$ of the fruit samples evaluated and in one of the three brands of commercial pulp. Among the OPPs pesticides, this is one of the most known active ingredients used in the farming community due to its wide spectrum utilization (formicide, acaricide, insecticide), and thus, it is indicated by legislation for application in the cultivation of various crops ${ }^{36}$ Nevertheless, the compound is not permitted for use in the cultivation of sapodilla, and thus, it should not be present in it. ${ }^{25}$ 
Table 4. Accuracies in terms of recovery with its RSDs (intra-assay precision) and repeatability precisions

\begin{tabular}{|c|c|c|c|c|c|c|c|}
\hline \multirow{3}{*}{ Pesticide } & \multicolumn{6}{|c|}{ Recovery (RSD / \%) / \% } & \multirow{3}{*}{$\begin{array}{c}\text { Precision } \\
(\mathrm{RSD} / \%)\end{array}$} \\
\hline & \multicolumn{6}{|c|}{ Spiked level / $\left(\mathrm{mg} \mathrm{kg}^{-1}\right)$} & \\
\hline & 0.08 & 0.10 & 0.14 & 0.20 & 0.35 & 1.17 & \\
\hline Dichlorvos & - & - & - & $71.3(4.1)$ & $75.5(9.8)$ & $104.2(12.6)$ & 9.35 \\
\hline Ethoprophos & $112.7(3.0)$ & $90.1(5.5)$ & $118.7(0.9)$ & $156.1(6.3)$ & $109.2(11.3)$ & $102.8(19.8)$ & 10.94 \\
\hline Disulfoton & $42.3(31.0)$ & $91.3(4.7)$ & $78.9(11.7)$ & $170.8(34.6)$ & $104.2(13.9)$ & $164.3(6.8)$ & 16.84 \\
\hline Parathion methyl & - & $85.3(8.8)$ & $77.3(27.0)$ & $85.8(6.5)$ & $111.6(6.0)$ & $114.2(3.5)$ & 12.27 \\
\hline Fenchlorphos & $63.7(12.4)$ & $70.3(6.1)$ & $85.9(4.8)$ & $67.9(22.3)$ & $84.0(8.8)$ & $95.1(3.5)$ & 5.63 \\
\hline Chlorpyrifos & $64.2(19.0)$ & $76.0(3.4)$ & $70.1(2.3)$ & $66.9(7.3)$ & $92.9(19.0)$ & $87.6(12.6)$ & 7.02 \\
\hline Prothiofos & $66.8(4.5)$ & $70.6(3.5)$ & $69.5(3.6)$ & $75.0(5.2)$ & $101.2(22.2)$ & $102.3(13.8)$ & 8.05 \\
\hline Azinphos methyl & - & - & - & $122.0(0.8)$ & $75.9(13.8)$ & $106.8(17.7)$ & 21.68 \\
\hline
\end{tabular}

RSD: relative standard deviation; -: spiked value less than LOQs of pesticides.

However, the results presented in Table 5 show that when compared with the MRLs of other samples, the levels obtained in the samples S7, S10 and B3 are a little irregular, and that one obtained at supermarket S6 showed a fairly significant level $\left(0.63 \mathrm{mg} \mathrm{kg}^{-1}\right)$.

Table 5. Results of analyzes of chlorpyrifos in samples of sapodilla fruits (S) and pulps (B) and similarity

\begin{tabular}{lcc}
\hline Chlorpyrifos & Concentration / $\left(\mathrm{mg} \mathrm{kg}^{-1}\right)$ & Similarity /\% \\
\hline S1 & n.d. & - \\
S2 & n.d. & - \\
S3 & $0.03 \pm 0.04$ & 43 \\
S4 & $<$ LOQ & 39 \\
S5 & $<$ LOQ & 32 \\
S6 & $0.63 \pm 0.02$ & 92 \\
S7 & $0.08 \pm 0.02$ & 92 \\
S8 & $<$ LOQ & 30 \\
S9 & n.d. & - \\
S10 & $0.12 \pm 0.04$ & 93 \\
B1 & n.d. & - \\
B2 & n.d. & - \\
B3 & $0.06 \pm 0.02$ & 88 \\
\hline
\end{tabular}

n.d.: not detected; LOQ: limit of quantification.

Comparing the value of chlorpyrifos found in S6 with the acceptable daily intake (ADI) set by EC $\left(0.001 \mathrm{mg} \mathrm{kg}^{-1}\right.$ b.w.) ${ }^{37}$ a person of $50 \mathrm{~kg}$ can consume up to $0.05 \mathrm{mg}$ of this pesticide per day. Knowing that, on average, sapodilla fruit sold in that supermarket has a mass of approximately $0.080 \mathrm{~kg}$; it is estimated that one fruit from the supermarket $\mathrm{S} 6$ would have enough chlorpyrifos residue to exceed the daily limit acceptable for this person. It is known that this pesticide has a level II toxicological classification, and in mammals, it acts by inhibiting the cholinesterase enzyme causing neurotoxic effects. ${ }^{38}$ Table 5 also shows the similarity of the chlorpyrifos mass spectrum obtained from the sample with the mass spectrum of its standard, where the samples S6, S7 and S10 have gotten more than $90 \%$ of possibility to really be the analyte.

The presence of pesticide residues in sapodilla samples has not been approached in the literature yet. The results indicate the need for studies to be expanded in the referred fruit plus the inclusion of this culture in the evaluations of national agencies such as ANVISA and INMETRO.

\section{Conclusions}

The QuEChERS/GC-MS method was a suitable technique for qualitative and quantitative analysis of organophosphorus pesticides in a sapodilla matrix. The validation parameters (selectivity, linearity, LODs, LOQs, accuracy and precision) proved to be satisfactory. The statistical evaluation of the linearity of the analytical curves indicates the insignificance of the linear coefficient for the compounds dichlorvos, fenchlorphos, chlorpyrifos and prothiofos. A strong matrix effect was observed for the eight OPPs compounds evaluated in this study, where the higher value was obtained for parathion methyl. The analyses of commercial samples demonstrated the increased use of commercial products containing the active ingredient chlorpyrifos by some farmers in the cultivation of sapodilla. This method can be efficiently applied to increase the scope of analysis of monitoring programs and improve food security.

\section{Acknowledgments}

The authors gratefully acknowledge the Coordination for the Improvement of Higher Education Personnel 
(CAPES) for financial support of this research and all of the infrastructure granted by the Trace Analysis Laboratory (LAT) of the Federal University of Ceará (UFC) and Multi-User Laboratory of Chemistry of Natural Products (LMQPN) of the Brazilian Company of Agricultural Research (Embrapa).

\section{References}

1. https://ww2.ibge.gov.br/home/estatistica/pesquisas/pesquisa resultados.php?id_pesquisa=44, accessed in May 2018.

2. Silva Junior, J. F.; Bezerra, J. E. F.; Ledermen, I. E.; Moura, R. J. M.; Rev. Bras. Frutic. 2014, 36, 86.

3. de Miranda, M. R. A.; Filgueiras, H. A. C.; Alves, R. E.; Soares, A. A.; Benbadis, A. K.; Rev. Ciênc. Agron. 2008, 39, 4.

4. Phan, K. T. K. P.; Phan, H. T.; Brennan, C. S.; Phimolsiripol, Y.; Int. J. Food Sci. Technol. 2017, 52, 2127.

5. http://www.abrasco.org.br/dossieagrotoxicos/wp-content/ uploads/2013/10/DossieAbrasco_2015_web.pdf, accessed in May 2018.

6. Bakirci, G. T. D.; Dilek, B. Y. A.; Bakirci, F.; Ötles, S.; Food Chem. 2014, 160, 379.

7. Akoto, O.; Gavor, S.; Appah, M. K.; Apau, J.; Environ. Monit. Assess. 2015, 187, 236.

8. Paz, M.; Correia-Sá, L.; Becker, H.; Longhinitti, E.; Domingues, V. F.; Food Control 2015, 54, 374.

9. http://portal.anvisa.gov.br/programa-de-analise-de-registro-deagrotoxicos-para, accessed in May 2018.

10. Savoy, V. L. T.; Biológico 2011, 73, 91.

11. Tang, Q.; J. Sep. Sci. 2014, 37, 820.

12. Seebunrueng, K.; Santaladchaiyakit, Y.; Srijaranai, S.; Talanta 2015, 132, 769.

13. Sapahin, H. A.; Makahleh, A.; Saad, B.; Arabian J. Chem. 2015, DOI: 10.1016/j.arabjc.2014.12.001.

14. Guedes, J. A. C.; Silva, R. O.; Lima, C. G.; Milhome, M. A. L.; Nascimento, R. F.; Food Chem. 2016, 199, 380.

15. Sousa, J. S.; Carius, C. R.; Andrade, G. A.; Lima, C. G.; Lima, L. K.; Milhome, M. A. L.; Nascimento, R. F.; Food Chem. 2013, $141,2675$.

16. Pavia, D. L.; Lampman, G. M.; Kriz, G. S.; Vyvyan, J. A.; Introduction to Spectroscopy, $5^{\text {th }}$ ed.; Cengage Learning: Stamford, USA, 2015.

17. Christia, C.; Bizani, E.; Christophoridis, C.; Fytianos, K.; Environ. Sci. Pollut. Res. 2015, 22, 13167.

18. Anastassiades, M.; Lehotay, S. J. S.; Tajnbaher, D.; Schenck, F. J.; J. AOAC Int. 2003, 86, 412.

19. Zhang, L.; Liu, S.; Cui, X.; Pan, C.; Zhang, A.; Chen, F.; Cent. Eur. J. Chem. 2012, 10, 900.
20. Vidal, J. L. M.; Frenich, A. G.; Methods in Biotechnology: Pesticide Protocols, vol. 19, $1^{\text {st }}$ ed.; Humana Press: Totowa, NJ, USA, 2005.

21. González-Curbelo, M. A.; Lehotay, S. J.; Hernández-Borges, J.; Rodriguez-Delgado, M. A.; J. Chromatogr. A 2014, 1358, 75.

22. Li, Y. F.; Qiao, L.; Li, F.; Ding, Y.; Yang, Z.; Wang, M.; J. Chromatogr. A 2014, 1361, 77.

23. https://ec.europa.eu/food/sites/food/files/plant/docs/pesticides_ mrl_guidelines_wrkdoc_2017-11813.pdf, accessed in February 2018.

24. Prestes, O. D.; Adaime, M. B.; Zanella, R.; Sci. Chromatogr. 2011, 3, 51.

25. http://portal.anvisa.gov.br/documents/10181/2721567/ RDC_166_201_COMP.pdf/d5fb92b3-6c6b-4130-86704e3263763401/, accessed in May 2018.

26. Harris, D. C.; Quantitative Chemical Analysis, $8^{\text {th }}$ ed.; Freeman and Company: New York, 2013.

27. Ligiero, C. B. P.; Reis, L. A.; Parrilha, G. L.; Baptista Filho, M.; Canela, M. C.; Quim. Nova 2009, 32, 1338.

28. Silva, C. M. S.; Habermann, G.; Marchi, M. R. R.; Zocolo, G. J.; Braz. Soc. Plant Physiol. 2012, 24, 223.

29. Pinho, G. P.; Neves, A. A.; Queiroz, M. E. L. R.; Silvério, F. O.; Quim. Nova 2009, 32, 987.

30. Pinho, G. P.; Silvério, F. O.; Neves, A. A.; Queiroz, M. E. L. R.; Quim. Nova 2012, 35, 738.

31. Erney, D. R.; Gillespie, A. M.; Gilvydis, D. M.; Poole, C. F.; J. Chromatogr. A 1993, 638, 57.

32. http://sitem.herts.ac.uk/aeru/ppdb/en/index.htm, accessed in May 2018.

33. Hajslová, J.; Holadova, K.; Kocourek, V.; Poustka, J.; Godula, M.; Cuhra, P.; Kempny, M.; J. Chromatogr. A 1998, 800, 283.

34. Martins, F. I. C. C.; Barbosa, P. G. A.; Zocolo, G. J.; Nascimento, R. F.; Chromatographia 2018, 81, 677.

35. Gomes, C. L.; Lima, A. C. A.; Barbosa, P. G. A.; Costa, R. S.; Melo, D. Q.; Nascimento, R. F.; J. Braz. Chem. Soc. 2017, 28, 2136.

36. Ribani, M.; Bottoli, C. B. G.; Collins, C. H.; Jardim, I. C. S. F.; Melo, L. F. C.; Quim. Nova 2004, 27, 771.

37. www.ec.europa.eu/food/plant/protection/resources/ qualcontrol_en.pdf, accessed in May 2018.

38. Venugopal, N. V. S.; Sumalatha, B.; Bonthula, S. R.; Orient. J. Chem. 2012, 28, 979.

Submitted: January 17, 2018

Published online: May 14, 2018 